\title{
Munc13-3 Superprimes Synaptic Vesicles at Granule Cell-to- Basket Cell Synapses in the Mouse Cerebellum
}

\author{
Shimpei Ishiyama, ${ }^{1}$ Hartmut Schmidt, ${ }^{1}$ Benjamin H. Cooper, ${ }^{2}$ Nils Brose, ${ }^{2}$ and ${ }^{-}$Jens Eilers ${ }^{1}$ \\ ${ }^{1}$ Carl Ludwig Institute for Physiology, Medical Faculty, University of Leipzig, D-04103 Leipzig, Germany, and 2Department of Molecular Neurobiology, Max \\ Planck Institute of Experimental Medicine, D-37075 Göttingen, Germany
}

\begin{abstract}
Munc13-3 is a presynaptic protein implicated in vesicle priming that is strongly expressed in cerebellar granule cells (GCs). Mice deficient of Munc13-3 (Munc13-3 $3^{-/-}$) show an increased paired-pulse ratio (PPR), which led to the hypothesis that Munc13-3 increases the release probability $\left(p_{\mathrm{r}}\right)$ of vesicles. In the present study, we analyzed unitary synaptic connections between GCs and basket cells in acute cerebellar slices from wild-type and Munc13-3 $3^{-/-}$mice. Unitary EPSCs recorded from Munc13-3 ${ }^{-1-}$ GCs showed normal kinetics and synaptic latency but a significantly increased PPR and fraction of synaptic failures. A quantal analysis revealed that neither the charge of single quanta nor the binominal parameter $N$ were affected by loss of Munc13-3 but that $p_{\mathrm{r}}$ was almost halved in $\mathrm{Munc13-3^{-1- }}$. Neither presynaptic $\mathrm{Ca}^{2+}$ influx was affected by deletion of Munc13-3 nor replenishment of the readily releasable vesicle pool. However, a high concentration of EGTA led to a reduction in EPSCs that was significantly stronger in $M u n c 13-3^{-/-}$. We conclude that Munc13-3 is responsible for an additional step of molecular and/or positional "superpriming" that substantially increases the efficacy of Ca ${ }^{2+}$. triggered release.
\end{abstract}

Key words: granule cell; Munc13; release probability; superpriming; vesicular release

\section{Introduction}

CNS neurons can fuse synaptic vesicles (SVs) with high temporal precision and fidelity during brief bursts of presynaptic action potentials (APs; Chadderton et al., 2004). The synaptic efficacy of such phasic transmission is influenced by several presynaptic and postsynaptic factors, among which the release probability $\left(p_{\mathrm{r}}\right)$ of SVs is functionally the most relevant parameter. It determines the amount of release in response to the first AP, which can be expected to be important for plasticity (Malinow and Tsien, 1990), reliability (Stevens and Wang, 1994), and speed of information processing in multistage neuronal networks (Thorpe et al., 1996). Via SV depletion, $p_{\mathrm{r}}$ also affects short-term plasticity (Fioravante and Regehr, 2011), allowing for redistributing synaptic efficacy within bursts (Markram and Tsodyks, 1996).

The $p_{\mathrm{r}}$ of an SV is set during molecular and positional priming, which renders SVs highly susceptible for release-triggering $\mathrm{Ca}^{2+}$ influx through voltage-gated $\mathrm{Ca}^{2+}$ channels. During priming, a complex interaction of proteins controls the intrinsic $\mathrm{Ca}^{2+}$

Received May 20, 2014; revised Sept. 17, 2014; accepted Sept. 22, 2014.

Author contributions: S.I., B.H.C., N.B., and J.E. designed research; S.I., H.S., and B.H.C. performed research; S.I., H.S., and B.H.C. analyzed data; S.I., N.B., and J.E. wrote the paper.

This work was supported by German Research Foundation research training group InterNeuro 1097 (J.E.), Grant SCHM1838/1 (H.S.), and Collaborative Research Centre 889/B1 (N.B.). We thank Gudrun Bethge for technical assistance and Manfred Heckmann and Stefan Hallermann for comments on this manuscript.

The authors declare no competing financial interests.

Correspondence should be addressed to Jens Eilers, Carl Ludwig Institute for Physiology, Medical Faculty, University of Leipzig, D-04103 Leipzig, Germany. E-mail: jens.eilers@medizin.uni-leipzig.de.

S. Ishiyama's present address: Bernstein Center for Computational Neuroscience, Humboldt University of Berlin, D-10115 Berlin, Germany.

DOI:10.1523/JNEUROSCI.2060-14.2014

Copyright $\odot 2014$ the authors $\quad 0270-6474 / 14 / 3414687-10 \$ 15.00 / 0$ sensitivity of the release machinery (molecular priming) and its coupling distance to $\mathrm{Ca}^{2+}$ channels (positional priming; Neher and Sakaba, 2008; Südhof, 2013). Munc13 proteins, mammalian homologs of Caenorhabditis elegans Unc-13, play distinct roles in SV priming (Brose et al., 2000). Of the four Munc13 isoforms (Munc13-1, ubMunc13-2, bMunc13-2, and Munc13-3) expressed in the brain (Betz et al., 2001), the ubiquitously expressed Munc13-1 (Augustin et al., 1999b) is essential for fusion competence of SVs in excitatory synapses (Augustin et al., 1999a). The remaining three Munc13s convey more subtle influences on SV release, which are isoform and apparently also cell-type specific. Munc13-3 is mainly expressed in the cerebellum, pons, brainstem (Augustin et al., 2001), visual cortex (Yang et al., 2002), and the calyx of Held (Chen et al., 2013). It is thought to regulate $p_{\mathrm{r}}$ in the cerebellum (Augustin et al., 2001; Beierlein et al., 2007; Bao et al., 2010) and potentially at the calyx of Held (Lee et al., 2013) to slow SV replenishment at the calyx of Held (Chen et al., 2013) and to play a role in network maturation in the visual cortex (Yang et al., 2002).

Here, we characterized the role of Munc13-3 at granule cell (GC)-to-basket cell (BC) synapses in cerebella from wild-type (WT) and Munc13-3-deficient [Munc13-3 $3^{-/}$(Augustin et al., 2001)] mice. Using paired recordings, $\mathrm{Ca}^{2+}$ imaging and application of a high concentration of the exogenous $\mathrm{Ca}^{2+}$ buffer EGTA, we provide direct evidence that Munc13-3 drastically increases $p_{\mathrm{r}}$ by enhancing $\mathrm{Ca}^{2+}$ release coupling via an additional priming step of either molecular or positional nature (Schlüter et al., 2006) but leaves all other parameters of transmission unaffected. We conclude that Munc13-3 superprimes SVs at GC-BC synapses. 


\section{Materials and Methods}

Animals. Homozygous Munc13-3 deletion mutant mice [Munc13-3 $3^{-1-}$ (Augustin et al., 2001)] with a C57BL/6 background were obtained by interbreeding of heterozygous mutant mice. Pups were genotyped by PCR with tail biopsy sampled at birth. Munc13-3 $3^{-1-}$ and C57BL/6 control mice (postnatal days 18-26, either sex) were anesthetized using isoflurane before decapitation. The cerebellum was removed and immediately immersed into ice-cold solution containing the following (in $\mathrm{mm}): 64 \mathrm{NaCl}, 25 \mathrm{NaHCO}_{3}, 2.5 \mathrm{KCl}, 1.25 \mathrm{NaH}_{2} \mathrm{PO}_{4}, 0.5 \mathrm{CaCl}_{2}, 7 \mathrm{MgCl}_{2}$, $10 \mathrm{D}$-glucose, and $120 \mathrm{D}$-sucrose, $\mathrm{pH} 7.4$ when aerated with carbogen $\left(95 \% \mathrm{O}_{2} / 5 \% \mathrm{CO}_{2}\right)$. Horizontal slices of the cerebellum (400 $\mu \mathrm{m}$ thickness) were prepared using a vibratome (VT1200S; Leica) and incubated at $35^{\circ} \mathrm{C}$ for $45 \mathrm{~min}$ in a solution containing the following (in $\mathrm{mM}$ ): 125 $\mathrm{NaCl}, 2.5 \mathrm{KCl}, 1.25 \mathrm{NaH}_{2} \mathrm{PO}_{4}, 26 \mathrm{NaHCO}_{3}, 1 \mathrm{MgCl}_{2}, 2 \mathrm{CaCl}_{2}, 20$ D-glucose, 3 myo-inositol, 4 Na-pyruvate (Serva Electrophoresis), 0.8 L-ascorbic acid, pH 7.4 when aerated with carbogen $(325 \mathrm{mOsm} / \mathrm{kg}$ adjusted by D-sucrose). Slices were then maintained at room temperature (RT) before starting experiments. Experimental procedures were approved by the local authority (state directorate of Saxony, Germany).

Electrophysiological recordings. The horizontal slices were placed in a recording chamber and perfused with a carbogen-gassed artificial CSF (ACSF) containing the following (in $\mathrm{mM}$ ): $125 \mathrm{NaCl}, 2.5 \mathrm{KCl}, 1.25$ $\mathrm{NaH}_{2} \mathrm{PO}_{4}, 26 \mathrm{NaHCO}_{3}, 1 \mathrm{MgCl}_{2}, 2 \mathrm{CaCl}_{2}, 20 \mathrm{D}$-glucose, and 0.01 of the $\mathrm{GABA}_{\mathrm{A}}$-receptor antagonist SR-95531 [2-(3-carboxypropyl)-3-amino6-(4-methoxyphenyl)pyridazinium bromide; Sigma-Aldrich], pH 7.4 (325 mOsm/kg adjusted by D-sucrose). The intracellular solution for whole-cell and cell-attached recordings consisted of the following (in mM): $150 \mathrm{KCl}, 3$ ATP-Mg, 0.3 GTP-Na, 10 HEPES-K, $10 \mathrm{NaCl}$, and 1 EGTA, pH $7.4(\sim 320 \mathrm{mOsm} / \mathrm{kg})$. Electrophysiological recordings were conducted at RT $\left(20 \pm 1^{\circ} \mathrm{C}\right)$ under optical control (BX51WI; Olympus) using an EPC10 amplifier controlled by PatchMaster 2.69 software (HEKA Elektronik). For whole-cell recordings and cell-attached stimulation, borosilicate glass pipettes (Hilgenberg) were pulled (PC-10; Narishige) to resistances of 5-6 $\mathrm{M} \Omega$ when filled with the intracellular solution. For tract stimulation, pipettes had 3-4 M $\Omega$ resistance when filled with ACSF. Tract stimulation was performed using ISO-STIM 01 DPI (npi electronic). Currents were filtered at $7 \mathrm{kHz}$ and sampled at 20 $\mathrm{kHz}$.

BCs were identified by the location of their somata in the lower third of the molecular layer and by their capability to generate APs. BCs were voltage clamped in the whole-cell configuration at a holding potential of $-80 \mathrm{mV}$ (corrected for the liquid junction potential). Once the wholecell configuration was established, the membrane capacitance cancellation was applied and the series resistance was compensated to limit the effective $R_{\mathrm{s}}$ to $\leq 10 \mathrm{M} \Omega$.

For paired recordings, putative presynaptic GCs were identified in a three-step procedure (Schmidt et al., 2013): first, the recording pipette was positioned in the GC layer close to the surface of the slice; brief pulses of positive pressure were applied to the pipette so that the ejected $\mathrm{K}^{+}$rich pipette solution would depolarize a patch of nearby GCs. Different locations were tested until bursts of EPSCs could be recorded in the postsynaptic $\mathrm{BC}$ in response to the pressure pulse, and duration and strength of the pressure pulse were kept minimal $(<500 \mathrm{~ms}$ and $<2$ mbar, respectively). Second, the recording pipette was lowered and a loose-cell recording was established with one of the GCs in the active area by applying slight negative pressure to the pipette; subsequently, the GC was depolarized for $50 \mathrm{~ms}$ with increasing voltage pulses until presynaptic action currents (ACs) were observed (typically 5 during the $50 \mathrm{~ms}$ depolarization). If the ACs were not associated with time-locked EPSCs in the $\mathrm{BC}$, the GC was discarded and, using the same pipette, a nearby GC was targeted. Third, once a connected GC had been identified, the stimulus intensity was established that reliably evoked only a single AC in response to a brief ( $1 \mathrm{~ms}$ ) depolarization of the GC [ $\sim 20 \%$ above the threshold of the AC $(100-300 \mathrm{mV})$, at a holding potential of $-80 \mathrm{mV}$ (Perkins, 2006)]; seal resistances ranged from 50 to $100 \mathrm{M} \Omega$. GCs located up to $30 \mu \mathrm{m}$ to each side under the $\mathrm{BC}$ soma were targeted so that the unitary EPSCs (uEPSCs) may have originated from ascending axons and/or parallel fibers.
Recordings were visually inspected for the absence of spontaneous ACs between stimuli. Paired-pulse stimulations were applied to the presynaptic GCs with interleaved interstimulus intervals (ISIs) of 10, 20, 50, $100,200,500$, and $1000 \mathrm{~ms}$, repeated sequentially every $5 \mathrm{~s}$. The PPR was calculated as the ratio of the mean charge of the second uEPSCs at a given ISI $\left(Q_{2}\right)$ to the mean charge of the first uEPSCs of all ISIs $\left(\bar{Q}_{1}\right)$. Charges were calculated over a period of $8.5 \mathrm{~ms}$ after the end of the presynaptic depolarization. The relationships between PPR and ISIs were fitted with a monoexponential function forced to return to unity.

Quantal parameters were estimated from GC-mediated uEPSCs recorded at different extracellular calcium concentrations $\left(\left[\mathrm{Ca}^{2+}\right]_{\mathrm{o}}: 1,2,5\right.$, or $10 \mathrm{mM}, \geq 80$ repetitions at each concentration, $5 \mathrm{~s}$ stimulus interval) by a multiple-probability fluctuation analysis (MPFA) well suited for unitary connections (Clements and Silver, 2000). In the MPFA, the variance of charges (corrected for the variance of visually identified failures) is plotted versus the mean charge (including failures), which allows extracting the quantal size $q, p_{\mathrm{r}}$, and the binomial parameter $N$ from a parabolic fit to the data (for details, see Hallermann et al., 2010). Estimates of $N$, which in theory should be integers but are reported as real numbers by the fitting routine, were rounded to one decimal place to reflect the uncertainty of the fit. Charges were calculated over a period of $8.5 \mathrm{~ms}$ after the end of the presynaptic depolarization, independent of whether a given responses would be visually identified as failure or success. To test whether the MPFA was distorted by postsynaptic receptor saturation, experiments were performed with EPSCs in BCs mediated by tract stimulation of parallel fibers (tEPSCs) recorded in the presence of $1 \mathrm{~mm}$ kynurenic acid in the ACSF (see Fig. $2 H$ ).

The distributions of failures and successes expected from the MPFA were superimposed on histograms of the charges recorded at the different $\mathrm{Ca}^{2+}$ concentrations (see Fig. 2C,F). The distributions were calculated from the estimated $N, q$, and $p_{\mathrm{r}}$ values by (1) rounding $N$ to the nearest integer, (2) setting the SD of failures to that of visually identified failures, (3) estimating the SD of single-quanta responses from a Gaussian fit to the binned charges around $q$, and (4) assuming that the mean and SD of multiquantal responses scale linearly with the number of released quanta.

For calcium buffer application experiments, EGTA-AM or BAPTA-AM (Invitrogen) dissolved in DMSO was aliquoted and stored at $-20^{\circ} \mathrm{C}$. Immediately before experiments, the aliquots were diluted in ACSF to their final concentration. Parallel fiber-mediated tEPSCs in BCs were recorded every $5 \mathrm{~s}$.

For quantifying vesicle replenishment, uEPSCs were recorded from BCs during train stimulation (30 pulses, at $100 \mathrm{~Hz}, 5 \mathrm{~min}$ interval) in presynaptic GCs.

$\mathrm{Ca}^{2+}$ imaging. GCs were held in the whole-cell configuration in current-clamp mode. The intracellular solution consisted of the following (in $\mathrm{mm}$ ): $150 \mathrm{~K}$-gluconate, $10 \mathrm{NaCl}, 3 \mathrm{ATP}-\mathrm{Mg}, 0.3 \mathrm{GTP}-\mathrm{Na}, 10$ HEPES, and 0.1 Oregon Green BAPTA-1 (OGB-1; Invitrogen). Imaging experiments were performed 20-40 min after the establishment of the whole-cell configuration. Single APs were generated by somatic current injection (200-400 pA for $1 \mathrm{~ms}$ ), and AP-mediated presynaptic $\mathrm{Ca}^{2+}$ transients were measured from individual boutons of GC axons in the point mode with a custom-build two-photon microscope that consists of a Fluoview 300 scanner (Olympus), a $60 \times / 0.90$ numerical aperture (NA) objective, and a mode-locked titanium:sapphire laser (Spectra-Physics; set to a central wavelength of $810 \mathrm{~nm}$ ). Fluorescence signals were recorded at $500 \mathrm{kHz}$ with an external photomultiplier tube module (Hamamatsu) and digitized via the Fluoview scanner. Fluorescence signals were temporally binned to $500 \mathrm{~Hz}$, background corrected, and represented as $\Delta F / F_{0}$ values.

Immunohistochemistry. Mice were killed at postnatal day 20 by decapitation under isoflurane anesthesia. Brains were removed and rapidly frozen in isopentane cooled to $-35^{\circ} \mathrm{C}$. Sagittal sections (20 $\mu \mathrm{m}$ thick) through the cerebellum were made at the cryostat and thaw-mounted on Superfrost slides. To ensure comparable fixation and labeling conditions between genotypes, sections from Munc13-1-enhanced yellow fluorescent protein (EYFP; Kalla et al., 2006) and Munc13-3-EGFP (Cooper et al., 2012) mice were collected on each slide, air dried for $15 \mathrm{~min}$, and immersion fixed in ice-cold 4\% paraformaldehyde solution (4\% PFA in 
0.1 M PB, pH 7.4) for $5 \mathrm{~min}$ at RT. Sections were incubated $90 \mathrm{~min}$ at RT in blocking solution $(0.1 \mathrm{M} \mathrm{PB}, 5 \%$ normal goat serum, $0.1 \%$ cold-water fish skin gelatin, and $0.5 \%$ Triton $\mathrm{X}-100, \mathrm{pH} 7.4)$ and then overnight at $4^{\circ} \mathrm{C}$ with primary antibodies (monoclonal rabbit anti-GFP, Invitrogen catalog \#G10362, 1:20; monoclonal mouse anti-bassoon, Enzo Life Sciences catalog \#SAP7F407) diluted in incubation buffer $(0.1 \mathrm{M} \mathrm{PB}, 3 \%$ normal goat serum, $0.1 \%$ cold-water fish skin gelatin, and $0.3 \%$ Triton $\mathrm{X}-100, \mathrm{pH}$ 7.4). Slides were washed extensively in $\mathrm{PB}$ and then incubated $2 \mathrm{~h}$ at RT in the dark with fluorescent secondary antibodies (Alexa Fluor 488-coupled goat anti-rabbit; Alexa Fluor 555-coupled goat anti-mouse; Alexa Fluor 633 goat anti-chicken; Invitrogen; 1:2000) diluted in incubation buffer. Coverslips were mounted on slides with Aqua-PolyMount (Polysciences).

Confocal laser scanning micrographs were acquired with a Leica TCSSP5 confocal microscope equipped with a tunable white light laser and hybrid gallium/arsenic/phosphorus detectors. Single-plane images of Munc13 and bassoon immunolabeling were acquired in sequential scanning mode using an HCX PL APO CS 100×, 1.4 NA oil-immersion objective corrected for coverslip thickness and a $6 \times$ zoom, resulting in pixel dimensions of $50.6 \mathrm{~nm}$ ( $x$ and $y$ ). Laser power and detector gains were optimized to ensure that all signals collected were in the linear range of detection. Individual micrographs were tiled throughout the cerebellar molecular layer and subsequently merged to provide an overview at high resolution.

The particle analysis feature of NIH Image J (version $1.47 \mathrm{q}$ ) was used to delineate the boundaries of bassoon-immunoreactive active zones within the cerebellar molecular layer, and the mean signal intensity of bassoon and GFP signals within the constraints of the active zones were measured. Identical parameters were applied to analyze both genotypes. The ratio of Munc13-XFP/bassoon signal intensity (Chen et al., 2013) was calculated for each pixel within the delineated active zone for creating ratio images (see Fig. $4 A, B$ ) or averaged per active zone for statistical analysis (see Fig. 4C).

The Colocalization plugin of NIH Image J was used to detect sites of colocalization between Munc13-1 and Bassoon (see Fig. 4D). Two signals were considered colocalized if their respective channel intensities exceeded an arbitrary threshold (set to 40 for both channels) and the ratio of pixel intensities for both channels exceeded 50\%. The number of individual colocalized sites was divided by either the total number of Bassoon puncta to estimate the relative proportion of active zones exhibiting colocalization with respective Munc13-XFPs or the total number of Munc13-XFP puncta to estimate the relative specificity with which respective Munc13-XFPs are localized to Bassoon-positive active zones in the cerebellar molecular layer. This analysis was repeated with horizontally flipped Bassoon images to estimate the contribution of incidental colocalization (Lipstein et al., 2013).

Statistical analysis. Normally distributed data (tested by Shapiro-Wilk test) are given as mean \pm SEM; intergroup comparisons were performed with Student's $t$ test. Data with non-normal distribution are given as median and interquartile ranges (IQRs); comparisons were done by Wilcoxon's rank-sum (Wrs) test. For comparisons of PPR, two-way repeated-measures ANOVA was used. The levels of significance are represented as ${ }^{*} p \leq 0.05,{ }^{* *} p \leq 0.01$, and ${ }^{* * *} p \leq 0.001 ; n$ refers to sample size. Data were analyzed with Igor Pro 6.22A (Wavemetrics), and statistical tests were performed using SigmaPlot 11 (Systat Software).

\section{Results}

EPSCs were recorded in cerebellar BCs, whereas single presynaptic GCs were stimulated in the cell-attached configuration. This configuration allowed for recording uEPSCs evoked by single presynaptic APs (Barbour, 1993). In the WT, individual uEPSCs showed rapid kinetics and a substantial variability in amplitude, synchronicity, and success in release (Fig. 1A). The low degree of synchronicity was not attributable to temporal imprecision of AP timing in the presynaptic GCs, which showed a jitter (SD) of $<100 \mu$ s per cell $(81 \pm 16 \mu$ s, mean \pm SEM; $n=12$ cells $)$. Instead, it was most likely attributable to the kinetics of the release machinery, which lead to release over several hundred mil- liseconds even after a single AP (Trigo et al., 2012; Schmidt et al., 2013). Synaptic responses could readily be visually classified as failures or successes (Fig. $1 B$ ), with typically $<2 \%$ ambiguous responses. The uEPSC charges showed a substantial (Fig. 1C, bottom) but stable scattering (Fig. $1 C$, top), with no indication of recruitment of silent synapses during the recording periods (Redman, 1990).

In unitary connections from Munc13-3 $3^{-/-}$mice, similar synaptic characteristics were observed (Fig. 1D). Temporal imprecision of presynaptic APs was again negligible (120 $\pm 32 \mu \mathrm{s}, n=10$; $p=0.25$ compared with the WT, $t$ test). Average uEPSCs (Fig. $1 A, D$, black traces) showed similar kinetics in all WT and Munc13-3 $3^{-/-}$connections. Values for $10-90 \%$ rise and decay times were $0.61 \mathrm{~ms}(0.45-0.84 \mathrm{~ms})$ and $2.60 \mathrm{~ms}(2.42-3.77 \mathrm{~ms})$ for WT (medians and IQRs; $n=14)$ and $0.54 \mathrm{~ms}(0.50-0.73 \mathrm{~ms})$ and $2.40 \mathrm{~ms}(1.88-3.78 \mathrm{~ms})$ for Munc13-3 ${ }^{-1-}(n=12)$, respectively (rise times, $p=0.82$; decay times, $p=0.40$; Wrs test). Correspondingly, the grand average WT and Munc13-3 $3^{-/}$ uEPSCs were indistinguishable when normalized to their peaks (Fig. 1E). We next quantified synaptic latencies as the time between presynaptic APs and the onset of uEPSCs in WT and Munc13-3 $3^{-1-}$ synapses (Fig. $1 F$ ). On average, both the median

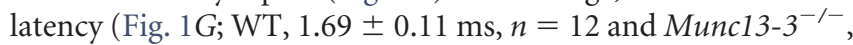
$1.55 \pm 0.09 \mathrm{~ms}, n=10$, mean \pm SEM) and the $10-90 \%$ range [Fig. 1H; WT, $0.99 \mathrm{~ms}(0.75-1.33 \mathrm{~ms})$ and Munc13-3 ${ }^{-1-}, 0.91 \mathrm{~ms}$ $(0.58-1.25 \mathrm{~ms})]$ were not different between the strains $(p=0.34$, $t$ test and $p=0.58$, Wrs test, respectively). These data indicate that the absence of Munc13-3 does not affect the time course of vesicular release.

In contrast to the kinetics, the averaged charge of uEPSCs (including failures) in Munc13-3 $3^{-/-}$synapses [-63 fC ( -22 to $-77 \mathrm{fC}), n=12]$ was smaller compared with the WT [ $-89 \mathrm{fC}$ $(-33$ to $-192 \mathrm{fC}), n=17$; Figure $1 I]$. However, this difference did not reach the level of significance ( $p=0.14$, Wrs test), presumably because of the substantial scatter of average responses across cells. Similarly, the average peak amplitudes of uEPSCs were not different between WT and Munc13-3 $3^{-1-}$ synapses $[-356 \mathrm{pA}(-156$ to $-1030 \mathrm{pA}), n=17$ and $-251 \mathrm{pA}(-87$ to $-361 \mathrm{pA}), n=12$, respectively; $p=0.088$, Wrs test]. Conversely, the fraction of synaptic failures was significantly larger in Munc13-3 $3^{-/-}$compared with WT connections $(0.66 \pm 0.06, n=$ 12 vs $0.48 \pm 0.06, n=17$, respectively, mean $\pm \mathrm{SEM} ;{ }^{*} p=0.043$, $t$ test; Fig. $1 J)$, indicating that either $p_{\mathrm{r}}$ or the number of release sites are decreased in Munc13-3 $3^{-1-}$ synapses.

Evidence for a Munc13-3-dependent effect on $p_{\mathrm{r}}$ had been obtained previously by analyzing EPSCs evoked by tract stimulation of bundles of GC axons (tEPSCs) in BCs (Bao et al., 2010), Golgi cells (Beierlein et al., 2007), and Purkinje cells (PCs) (Augustin et al., 2001; Beierlein et al., 2007; but see Bao et al., 2010). For these GC connections, an increase in paired-pulse facilitation (PPF) was observed in Munc13-3 $3^{-1-}$ mice. We reexamined this finding at unitary GC-BC connections with paired presynaptic stimulations applied at different ISIs (Fig. $1 K$ ). To minimize the effect of synaptic jitter, PPRs were calculated as the average charge of the second uEPSCs at each ISI divided by the charge of the first uEPSCs averaged over all ISIs. Both, WT and Munc13-3-1- synapses displayed a strong facilitation at short ISIs that decreased to unity at intervals of 500-1000 ms. At an ISI of $10 \mathrm{~ms}$, PPR was $2.7 \pm 0.2$ (mean \pm SEM, $n=14)$ in the WT but $3.5 \pm 0.3(n=12)$ in Munc13-3 $3^{-1-}$ mice, values in good agreement with the previous studies. The increased facilitation was statistically significant $\left({ }^{*} p=0.04\right.$, two-way repeated-measures ANOVA). 


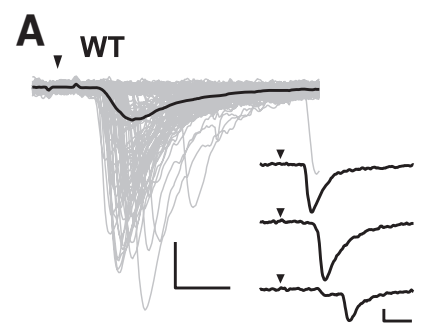

B

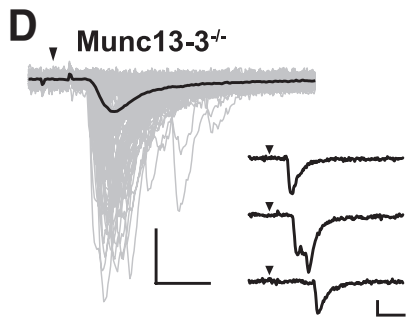

E

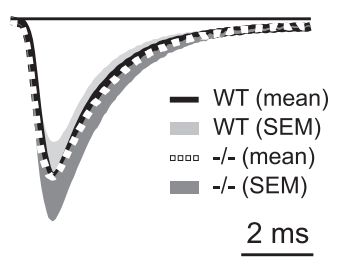

C

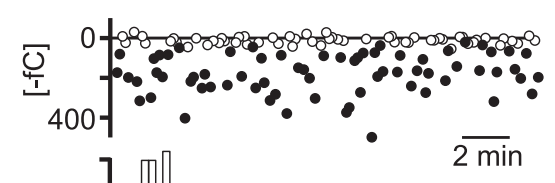

$\varepsilon$

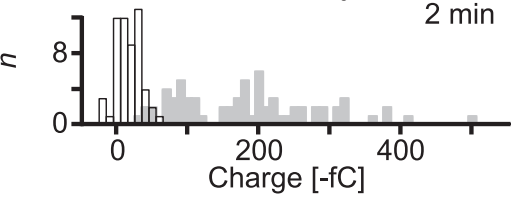

F

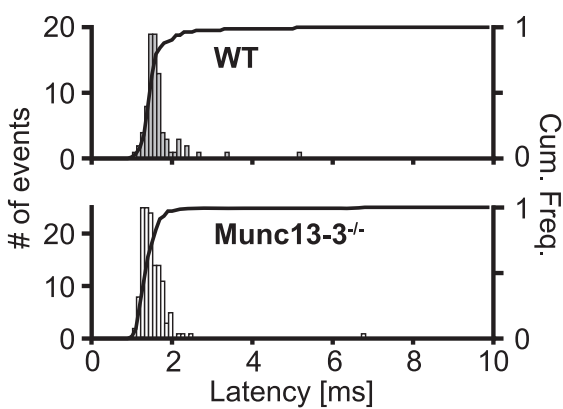

K

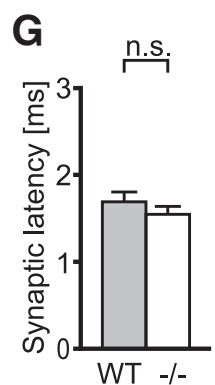

(12)(10)

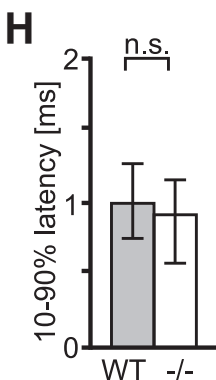

(12) (10)

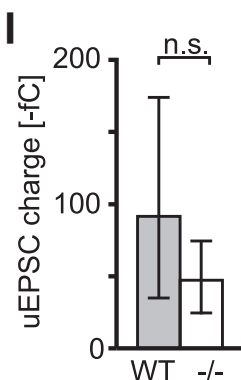

(17) (12)

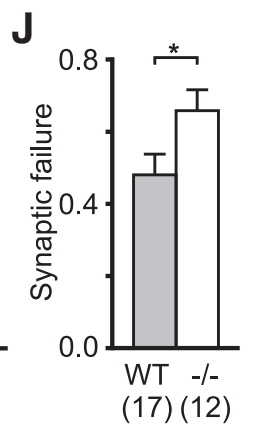

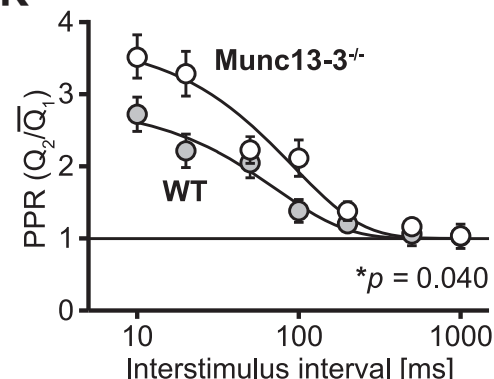

Figure 1. Increase in synaptic failure and facilitation in $M$ unc $13-3^{-1-}$ synapses. $A$, Left, 0 verlay of successive uEPSCs (gray; $n=125$, including failures) from a WT GC-BC connection. The average uEPSC is shown in black. The arrowhead denotes the time point of the presynaptic ACs, which showed a jitter of $<100 \mu \mathrm{S}$ (SD) that was ignored in the averaging procedure. The small deflections in the average trace correspond to the stimulation artifact from the presynaptic depolarization. Bottom right, Example uEPSCs illustrating the variability of release. Calibration: $50 \mathrm{pA}, 2 \mathrm{~ms}$. $\boldsymbol{B}$, Expanded view of visually identified failures (top traces) and peak-aligned successes (bottom traces; peaks were clipped for clarity) from $A$. Calibration: $5 \mathrm{pA}, 500 \mu \mathrm{s}$. C, Top, Sequence of responses classified as failures (open circles) or success (filled circles). Bottom, Corresponding histograms (open bars, failures; gray bars, successes). Same experiment as in $\boldsymbol{A}$ and $\boldsymbol{B}$. $\boldsymbol{D}$, Same as in $\boldsymbol{A}$ but for a Munc $13-3^{-1-}$ synapse (gray, $n=172$; average in black). $\boldsymbol{E}$, Grand averages of uEPSCs from WT and Munc $13-3^{-1-}$ synapses (black and stippled lines, $n=17$ and 12 , respectively). Average uEPSCs from individual $\mathrm{GC}-\mathrm{BC}$ connections were normalized to their peaks before grand averaging. SEM values are given in one direction only. Note the similar waveform of WT and Munc13-3 ${ }^{-/-}$uEPSCS. $\boldsymbol{F}$, Example histograms and cumulative frequencies (Cum. Freq.) of synaptic latencies in a WT (top) and a Munc13-3 ${ }^{-1-}$ (bottom) unitary GC-BC connection ( $n=83$ and 135 , respectively; latency is the time between the peak of the presynaptic AC and the onset of the uEPS(S, measured for each uEPSC, excluding failures). G, Average (across cells) of median (per cell) synaptic latency in WT and Munc $13-3^{-1-}$ synapses (mean \pm SEM; $p=0.34, t$ test). Cell numbers are denoted in parentheses. $\boldsymbol{H}$, The $10-90 \%$ range of the cumulative frequency of synaptic latency (median and IQR; $p=$ 0.58 , Wrs test). I, Average charge of uEPSCs (calculated over a period of $8.5 \mathrm{~ms}$ after the end of the presynaptic depolarization) for WT and Munc $13-3^{-/-}$synapses (given as median and IQRs; $p=$ 0.138 , Wrs test). $\boldsymbol{J}$, Fraction of synaptic failures averaged per cells (mean $\pm \mathrm{SEM} ;{ }^{*} p=0.043, t$ test). $\boldsymbol{K}$, Group analysis of PPRs versus ISI in unitary GC-BC connections. PPR was calculated per cell as the averaged second charge $\left(Q_{2}\right)$ over the first charge averaged over all ISIs $\left(\bar{Q}_{1} ; \mathrm{WT}, n=14\right.$ at an ISI of $10-200 \mathrm{~ms}, n=8$ at an ISI of $500-1000 \mathrm{~ms} ; M_{4}$ unc $13-3^{-1-}, n=12 ;$ mean \pm SEM; ${ }^{*} p=$ 0.040, two-way repeated-measures ANOVA). The smooth curves represent monoexponential fits (forced to return to unity) to the group data, yielding time constants of 73 and $91 \mathrm{~ms}$ for WT and Munc $13-3^{-1-}$ PPRs, respectively.

To substantiate and quantify possible effects of Munc13-3 on $p_{r}$, we performed MPFAs (Clements and Silver, 2000) on uEPSC charges recorded at different $\left[\mathrm{Ca}^{2+}\right]_{0}$. Figure $2 A$ illustrates a typical WT example. While uEPSCs recorded at $2 \mathrm{~mm}\left[\mathrm{Ca}^{2+}\right]_{\mathrm{o}}$ showed a substantial variability, failures dominated at $1 \mathrm{~mm}$ $\left[\mathrm{Ca}^{2+}\right]_{\mathrm{o}}$ and large uEPSCs at $10 \mathrm{~mm}$. The corresponding variance versus mean relationship (Fig. $2 B$ ) allowed extracting the $q, N$, and $p_{\mathrm{r}}$ (discussed in the following for $2 \mathrm{~mm}\left[\mathrm{Ca}^{2+}\right]_{\mathrm{o}}$ only). The appropriateness of the obtained quantal parameters was tested by calculating the corresponding expected distributions of failures and successes (for details, see Materials and Methods). These distributions matched well the histogrammed responses at the different $\mathrm{Ca}^{2+}$ concentrations, especially the probability of failures (Fig. 2C).

MPFAs performed in WT and Munc13-3 $3^{-1-}$ GC-BC connections (Fig. 2D-F) revealed that the absence of Munc13-3 affected neither $q(-154 \pm 26 \mathrm{vs}-123 \pm 22 \mathrm{fC}$, mean $\pm \mathrm{SEM} ; p=0.40$, $t$ test $)$ nor $N(2.2 \pm 0.6$ vs $2.6 \pm 0.8 ; p=0.68 ; n=6$ each $)$. However, $p_{\mathrm{r}}$ was significantly lower in Munc13-3 $3^{-1-}$ synapses $(0.24 \pm 0.04)$ compared with the WT $\left(0.38 \pm 0.05 ;{ }^{*} p=0.043\right.$; Fig. $2 G$, right). As expected, the products of the average $N, q$, and $p_{\mathrm{r}}$ values for WT and Munc13-3 $3^{-/-}$connections $(129 \pm 45$ and $77 \pm 30 \mathrm{fC}$, respectively, mean \pm SEM) and the average of the products per cell (128 \pm 35 and $51 \pm 10 \mathrm{fC}$, respectively) were similar to the median uEPSC charges (Fig. 1I).

The possibility that postsynaptic receptor saturation distorted the MPFA was addressed by control experiments in which the effect of the rapidly dissociating glutamate receptor antagonist kynurenic acid on tEPSCs of GC axons in the WT (Meyer et al., $2001)$ was analyzed. The MPFA of tEPSCs yielded $p_{\mathrm{r}}$ values $(0.43 \pm$ 0.06 , mean \pm SEM; $n=6$; Fig. $2 H$, Ctr) similar to those obtained from uEPSCs in the WT ( $p=0.54, t$ test). Application of kynurenic 
A
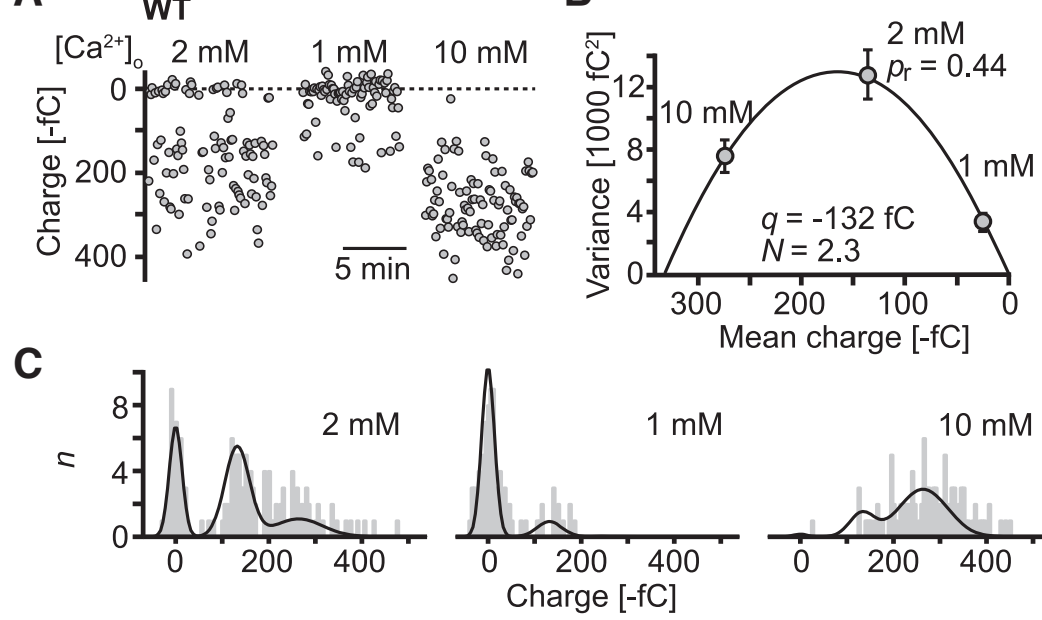

D

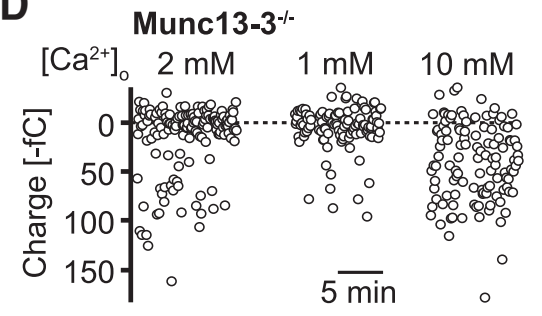

$\mathbf{F}$
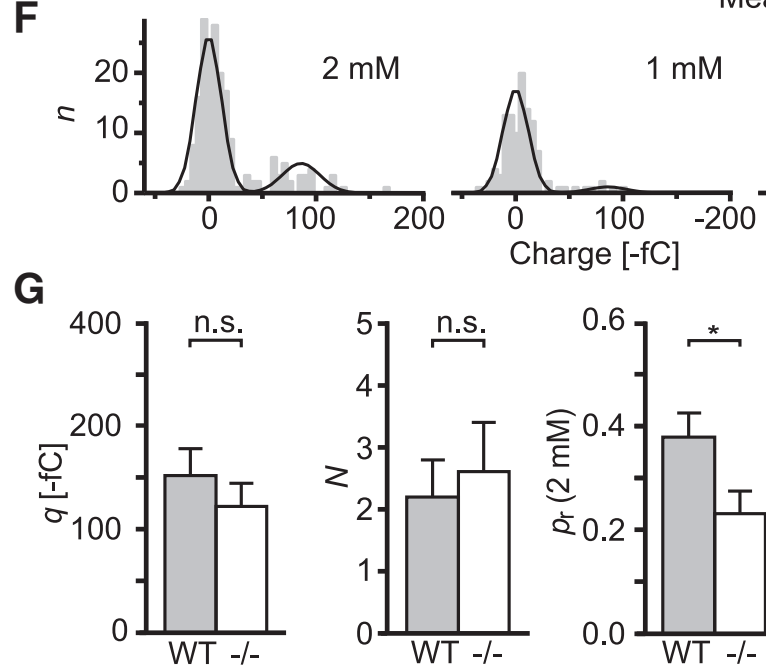

(6) (6)

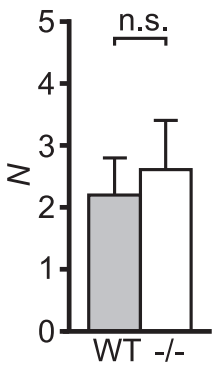

(6) (6)

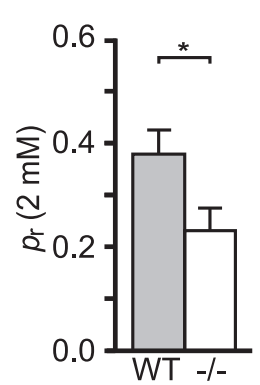

(6) (6)

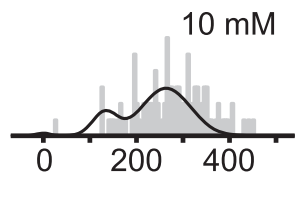

E
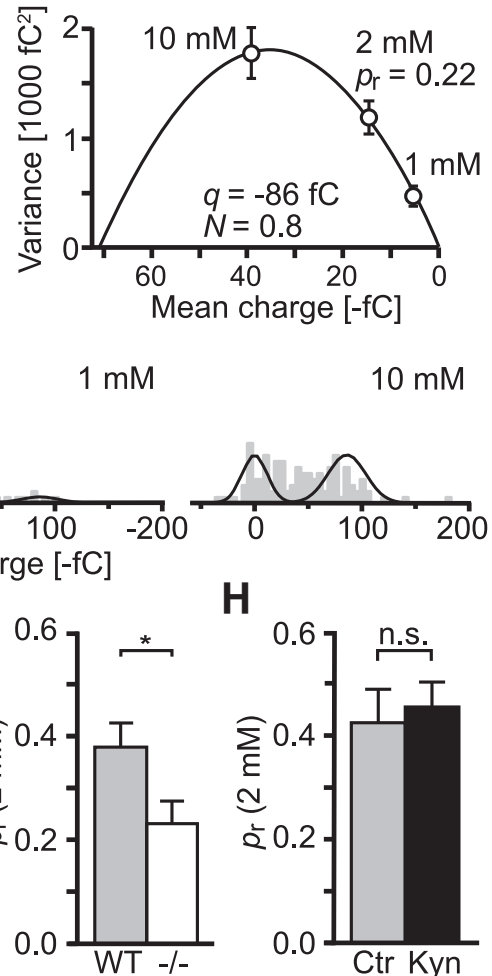

(6) (6)

Figure 2. Decreased $p_{\mathrm{r}}$ but unaltered quantal size and binomial parameter at Munc13-3 $3^{-1-}$ synapses. $\boldsymbol{A}$, Charges of GCmediated uEPSCs in a WT BC recorded at different $\left[\mathrm{Ca}^{2+}\right]_{0}(2 \mathrm{~mm}, n=99 ; 1 \mathrm{~mm}, n=83 ; 10 \mathrm{~mm}, n=95)$. Responses during the wash phases were omitted for clarity. $\boldsymbol{B}$, Variance-mean plot of the data shown in $\boldsymbol{A}$. Error bars denote the SD of the variance. The line represents a parabolic fit, constrained through the origin, which yielded $q, N$, and $p_{r}$. $\boldsymbol{C}$, Histograms of the charges (including failures; bin size, $10 \mathrm{fC}$ ) recorded at the indicated $\mathrm{Ca}^{2+}$ concentrations. Superimposed (smooth curves) are the expected distributions of failures and successes (for details, see Materials and Methods). D-F, Same as in $\boldsymbol{A}-\boldsymbol{C}$ but for a Munc $13-3^{-/-}$connection. G, Average $q, N$, and $p_{\mathrm{r}}$ values of WT and Munc $13-3^{-1-}$ synapses (mean \pm SEM). The $p$ values are $0.402,0.678$, and 0.043 for $q$, $N$, and $p_{\mathrm{r}}$, respectively; $t$ test. Cell numbers are denoted in parentheses. $\boldsymbol{H}$, Average $p_{\mathrm{r}}$ at $2 \mathrm{~mm}\left[\mathrm{Ca}^{2+}\right]_{0}$ in the WT in the absence (Ctr) or presence of $1 \mathrm{~mm}$ kynurenic acid in the extracellular solution (Kyn). Mean $\pm \mathrm{SEM} ; p=0.717, t$ test; cell numbers are denoted in parentheses. EPSCs were evoked by tract stimulation.

acid $(1 \mathrm{mM}$ ) reduced tEPSCs charges to $28 \pm 14 \%$ (mean \pm SEM, $n=3)$. However, the corresponding estimate of $p_{\mathrm{r}}(0.46 \pm 0.05, n=$ 6 ; Fig. $2 \mathrm{H}, \mathrm{Kyn})$ was not different from the control result $(p=0.72$, $t$ test). Therefore, in line with the increased failure rate (Fig. $1 J$ ) and the increase in PPR (Fig. $1 K$ ), the MPFA provides strong evidence that $p_{\mathrm{r}}$ is almost halved (Fig. 2G) in the absence of Munc13-3.

Reduced presynaptic $\mathrm{Ca}^{2+}$ transients represent a possible mechanism for reductions in $p_{\mathrm{r}}$ (cf. Kaeser et al., 2011; Kintscher et al., 2013). Therefore, we performed $\mathrm{Ca}^{2+}$ imaging experiments and investigated whether AP-induced $\mathrm{Ca}^{2+}$ transients are altered in $\mathrm{Munc13-3^{-1- }}$ terminals (Fig. 3A). GCs were equilibrated for $20 \mathrm{~min}$ in the whole-cell configuration with the high-affinity $\mathrm{Ca}^{2+}$ indicator OGB-1 $(100 \mu \mathrm{M})$, a loading time that allowed visualizing putative presynaptic boutons (Fig. 3A, left inset). Single APs evoked nonsaturated fluorescent signals $\left(\Delta F / F_{0}\right)$ (Schmidt et al., 2003) with little variability per bouton (Fig. $3 A$, right inset) and between cells (Fig. $3 B$ ). On average, $\Delta F / F_{0}$ amplitudes were not different in WT and Munc13-3 ${ }^{-/-}$boutons ( $0.84 \pm$ 0.11 vs $0.83 \pm 0.16$, mean $\pm \mathrm{SEM} ; n=6$ cells each, 34 and 33 boutons in total; $p=$ 0.97, $t$ test; Fig. 3B).

The boutons on which $\mathrm{Ca}^{2+}$ imaging experiments were performed most likely represent contacts with different postsynaptic targets. Given that Munc13-3 $3^{-/-}$ GCs show alterations in PPF that are target-cell specific (Beierlein et al., 2007; Bao et al., 2010), we tested the possibility that Munc13-3 locates to a subset of GC terminals only. Inadequate sampling of such terminals could have biased our $\mathrm{Ca}^{2+}$ imaging data. To this end, we performed a quantitative immunohistochemistry analysis on cerebellar slices from mice in which either Munc13-1 (Kalla et al., 2006) or Munc13-3 (Cooper et al., 2012) were tagged with EYFP or EGFP, respectively. Antibody staining for Bassoon served as a marker for presynaptic active zones. Munc13-1-EYFP showed a homogenous expression throughout the molecular layer of the cerebellar cortex (Fig. 4A,C). Munc13-3-EGFP showed a weaker but also homogenous staining (Fig. 4B,C). Importantly, Munc13-3 was detected at the majority of active zones within the molecular layer (Fig. 4D) and showed no indication of being specifically localized to distinct subclasses of terminals with exceptionally low or high protein levels. Together, our $\mathrm{Ca}^{2+}$ imaging and immunohistochemistry data indicate that the reduced $p_{\mathrm{r}}$ in $\mathrm{Munc} 13-3^{-1-}$ cells is not attributable to a decreased APevoked $\mathrm{Ca}^{2+}$ influx. Therefore, two other plausible mechanisms explaining the difference in $p_{r}$ were addressed: a slower rate of SV replenishment and imperfect molecular/positional priming leading to deteriorated release process.

Replenishment of released SVs depends on members of the Munc13 family (Lipstein et al., 2012, 2013) and may affect repeatedly evoked uEPSCs even at the long stimulus intervals ( $5 \mathrm{~s}$ ) used 
in the MPFA (Valera et al., 2012). To compare replenishment rates at WT and Munc13-3 $3^{-1-}$ synapses, we performed train stimulations ( $100 \mathrm{~Hz}$ for $300 \mathrm{~ms}$ ) at unitary GC-BC connections (Fig. $5 A, B$ ). In both genotypes, the cumulative charge during the train showed two distinct components. A rapid, initial component (lasting $\sim 100 \mathrm{~ms}$ ), representing release of readily releasable SVs, and a second, slow component determined by replenishment of SVs and, possibly, postsynaptic receptor desensitization (Schneggenburger et al., 1999). Extrapolating the second, slower component to the beginning of the train stimulation (Fig. $5 A, B, y$-intercepts of dashed lines) allowed estimating the amount of release from the readily releasable SV pool (RRP). On average, WT and Munc13-3 ${ }^{-/-}$synapses showed similar $y$-intercepts [WT, $-0.69 \mathrm{pC}(-0.51$ to $-5.66 \mathrm{pC})$, Munc13-3 ${ }^{-/-},-1.25 \mathrm{pC}$ $(-0.62$ to $-2.27 \mathrm{pC}) ; n=7$ each; $p>$ $0.05, \mathrm{Wrs}$ test]. Considering the average $q$ and $N$ obtained from the MPFAs (Fig. 2), the $y$-intercepts are approximately twofold larger than expected in both genotypes. In agreement with Valera et al. (2012), this indicates that additional release sites may have been recruited during the high-frequency trains, importantly to the same degree in WT and Munc13-3 $3^{-1-}$ synapses.

The slope of the slow component was also not different between the genotypes (WT, $-12.9 \pm 8.0 \mathrm{pC} / \mathrm{s}$ and Munc13-3 $3^{-/-}$, $-16.2 \pm 10.6 \mathrm{pC} / \mathrm{s}$, respectively, mean \pm SEM; $n=7$ each; $p=0.52$, $t$ test; Fig. $5 C$ ). Assuming that postsynaptic effects affect the slow component to the same degree in both genotypes, the train experiments indicate that replenishment of released SVs is not affected by the absence of Munc13$3^{-1-}$. This leaves imperfect priming as the remaining explanation for the functional deficit in Munc13-3 $3^{-/-}$synapses.

To this end, we quantified the degree by which high concentrations of the slow $\mathrm{Ca}^{2+}$ buffer EGTA (Eggermann et al., 2012) affects release in WT and Munc13-3 $3^{-1-}$ synapses. GC synapses, at least when contacting PCs, most likely operate at nanodomain coupling and, therefore, are insensitive to $10 \mu \mathrm{M}$ EGTA-AM but not to $10 \mu \mathrm{M}$ of the fast $\mathrm{Ca}^{2+}$ buffer BAPTA-AM (Schmidt et al., 2013). We found a similar buffer sensitivity at GC-BC connections (Fig. $6 A, B)$, suggesting that they also operate with tight influx-release coupling. Buffering effects in the nanodomain are determined by the product of the on-rate and the buffer concentration ("buffer product"; $\mathrm{Ne}$ her, 1998). Assuming similar effectiveness of loading and deesterification for BAPTA- and EGTA-AM, we reasoned that 100
A

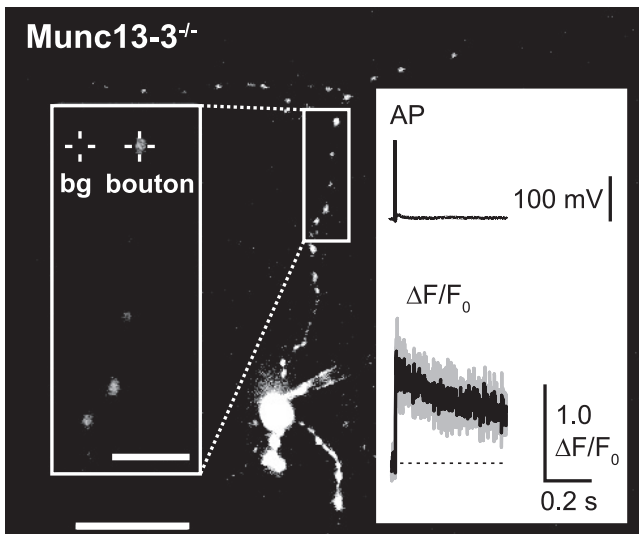

B

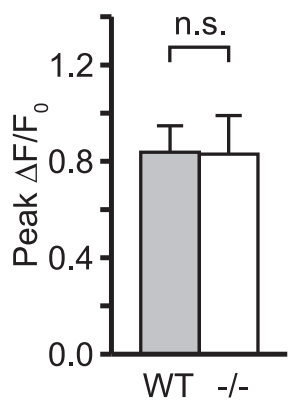

(6) (6)

Figure 3. Normal $\mathrm{Ca}^{2+}$ transient in Munc13-3 $3^{-/-}$terminals. A, Two-photon image of a Munc13-3 $3^{-1-} \mathrm{GC}$ filled with the $\mathrm{Ca}^{2+}$ indicator dye OGB-1 $(100 \mu \mathrm{M})$ via a somatic patch pipette. The box indicates the axonal region enlarged in the left inset in which $\mathrm{Ca}^{2+}$ imaging (point mode) on single boutons were performed. The crosshairs indicate a single bouton and the corresponding background region (bg). Right top trace, AP evoked by somatic depolarization. Right bottom trace, Single-AP evoked fluorescent transient from the bouton indicated in the left inset (gray, $n=3$ repetitions; average in black). Scale bars: 20 and $5 \mu \mathrm{m}$. $\boldsymbol{B}$, Peak $\Delta F / F_{0}$ averaged over all boutons $(\geq 2)$ per cell (mean \pm SEM; $p=0.97, t$ test). Cell numbers are denoted in parentheses.

A
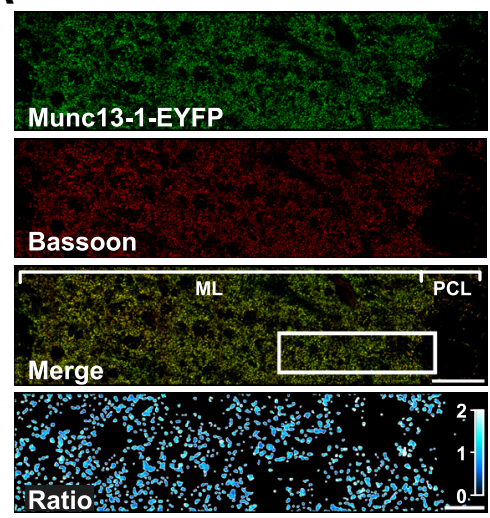

C

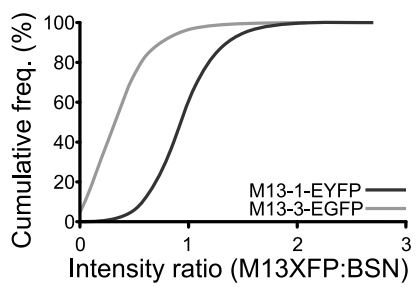

B
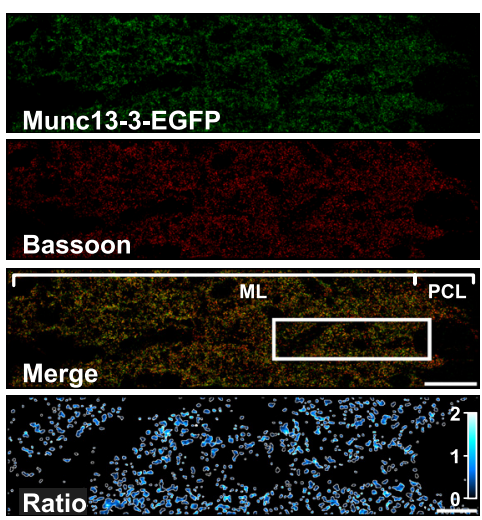

D

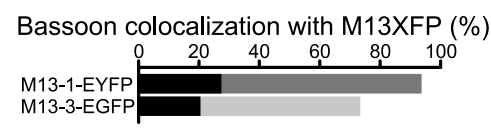

M13XFP colocalization with Bassoon (\%)

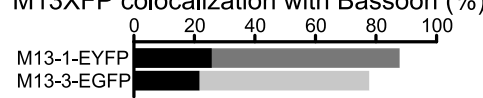

Figure 4. Homogenous distribution of Munc13-1 and Munc13-3 in the molecular layer. $A, B$, Sagittal cerebellar sections from a pair of Munc13-1-EYFP $(\boldsymbol{A})$ and Munc13-3-EGFP $(\boldsymbol{B})$ knock-in mice. Respective Munc13 isoforms were labeled with an anti-GFP antibody (green), and the active zone protein Bassoon was labeled with an anti-Bassoon antibody (red). Each image was assembled from tiles $(26 \times 26 \mu \mathrm{m}, 512 \times 512$ pixels) throughout the cerebellar molecular layer. The boxed regions in the merged images are shown at higher magnification as ratio images. Here, putative active zones (identified by thresholding the Bassoon signal) are delineated, and the color coding represents the respective Munc13 isoform/Bassoon ratio. Light blue indicates higher and dark blue lower relative Munc13 contents. Scale bars: Merge, $20 \mu \mathrm{m}$; Ratio, $5 \mu \mathrm{m}$. ML, Molecular layer; PCL, Purkinje cell layer. C, Cumulative frequency distribution of the Munc13-1/Bassoon and Munc13-3/Bassoon ratios (dark and light gray, $n=5593$ and 5170, respectively) of putative active zones. $\boldsymbol{D}$, Bar graphs illustrating the percentages of putative active zones in which Bassoon colocalized with Munc13-1 or Munc13-3 (top graph) and in which Munc13-1 or Munc13-3 puncta colocalized with Bassoon (bottom graph). The black bars indicate the respective contribution of coincidental colocalization, calculated by horizontally flipping the Bassoon channel before top analysis.

$\mu \mathrm{M}$ EGTA-AM would be comparable with 1-10 $\mu \mathrm{M}$ BAPTA-AM (Neher, 1998; Eggermann et al., 2012). At this high concentration, the buffer product of EGTA would be strong enough to interfere even with nanodomain coupling (Bucurenciu et al., 
A

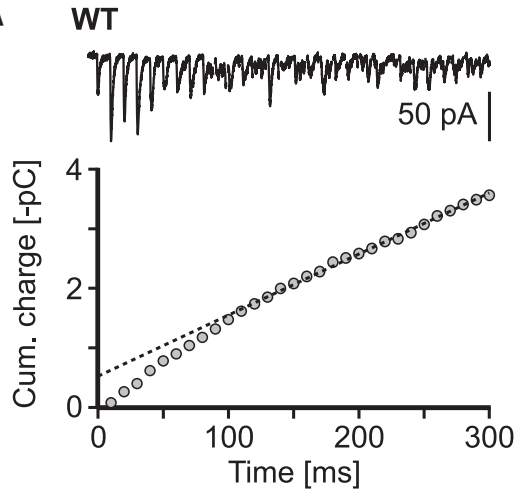

B

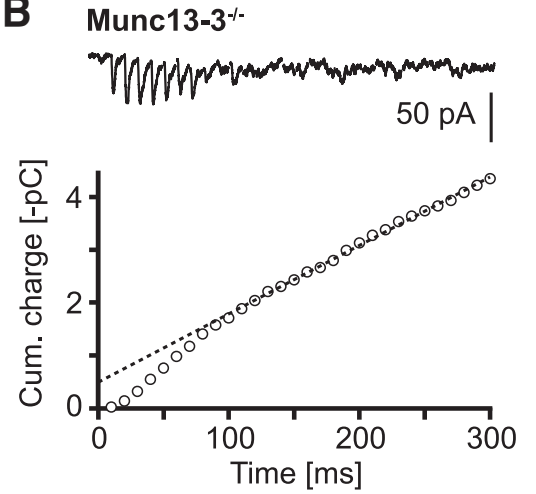

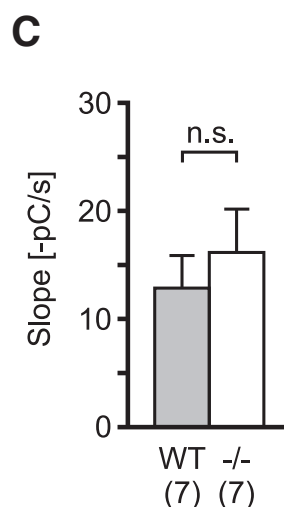

Figure 5. Normal vesicle replenishment in Munc $13-3^{-1-}$ synapses. $A$, Top, Train stimulation ( $100 \mathrm{~Hz}, 300 \mathrm{~ms}$; average of 5 successive recordings) of a unitary WT GC-BC connection. Stimulation artifacts are blanked for clarity. Bottom, Cumulative charge (before each stimulus) of the top trace. The dashed line represents an extrapolation of the slow component (100 $-300 \mathrm{~ms}$ ) to $t=0 . \boldsymbol{B}$, Same as in $A$ but for a Munc $13-3^{-1-}$ synapse. $C$, Average slope of the slow component in recordings from WT and Munc $13-3^{-/-}$synapses; $p=0.52, t$ test. Cell numbers are denoted in parentheses.

2008) and reveal changes in positional priming and/or the intrinsic $\mathrm{Ca}^{2+}$ sensitivity of the release machinery. Figure $6 \mathrm{C}$ illustrates typical example experiments from WT and Munc13-3 $3^{-1-}$ cells. EPSCs evoked by tract stimulation were recorded while membrane-permeable EGTA-AM $(100 \mu \mathrm{M})$ was applied for 10 min. Both WT and Munc13-3 $3^{-1-}$ synapses showed an EGTAdependent reduction in tEPSC charge (Fig. 6C). No EGTAdependent effects on the waveform of the tEPSCs were observed (Fig. 6D), indicating that, at a given synapse, release occurs from SVs with a homogenous $\mathrm{Ca}^{2+}$ sensitivity. Notably, however, the reduction of tEPSCs was significantly stronger in Munc13-3 $3^{-/-}$synapses compared with the WT (WT, $25 \pm 3 \%, n=10$; Munc13- $3^{-/-}$, $43 \pm 5 \%, n=12$; mean \pm SEM; ${ }^{* *} p=0.009, t$ test; Fig. $\left.6 F\right)$, indicating that imperfect priming significantly reduced release probability in the absence of Munc13-3.

\section{Discussion}

Our data, representing the first quantitative report of paired recordings between GCs and BCs, show that Munc13-3 acts as a priming factor at cerebellar GC synapses that almost doubles $p_{\mathrm{r}}$ of SVs but leaves other key parameters of synaptic transmission, such as presynaptic $\mathrm{Ca}^{2+}$ dynamics, kinetics of release, SV replenishment, availability of release sites, and postsynaptic responsiveness, undisturbed. These findings indicate that Munc13-3, in addition to its role in recruiting SVs to the RRP at the calyx of Held (Chen et al., 2013), can superprime SVs that are otherwise fully matured and release ready (Fig. $6 F$ ), similar to the superpriming mediated by complexins (Südhof, 2013) and Rab3 (Schlüter et al., 2006) and suggested for Munc13s at the calyx of Held (Lee et al., 2013). As for Rab3, two alternative mechanisms may explain the effect that Munc13-3 exerts on $p_{\mathrm{r}}$. Munc13-3 may enhance the intrinsic $\mathrm{Ca}^{2+}$ sensitivity of the release machinery, for example, by pulling it closer to the plasma membrane ("molecular superpriming"; as suggested for complexins and Munc13s) or it may tighten the coupling between $\mathrm{Ca}^{2+}$ channels and release-ready SVs ("positional superpriming"). Distinguishing between these two potential modes of superpriming, which are not mutually exclusive, remains a challenging experimental task (Schlüter et al., 2006).

Previous studies on the role of Munc13-3 in cerebellar GCs are consistent with our findings. The original analyses of Munc13-3deficient mutant mice (Augustin et al., 2001) indicated an increased PPF of tEPSCs recorded in PCs. The authors proposed that this change in short-term plasticity is attributable to a Munc13-3-dependent increase in $p_{\mathrm{r}}$. The same conclusion was drawn by Beierlein et al. (2007) and Bao et al. (2010) who found a Munc13-3-dependent PPF also in GC inputs to Golgi cells and BCs, respectively. Interestingly, Bao et al. (2010) reported on a substantial smaller facilitation compared with our data. They used repeated burst stimulations to quantify PPF, a stimulus paradigm known to induce presynaptic long-term potentiation associated with rapidly occurring reductions in PPF in GCs (Salin et al., 1996). Accordingly, the larger relative effect of Munc-13-3 reported by Bao et al. (2010) may be taken as evidence for a role of Munc13-3 in presynaptic plasticity.

However, factors other than $p_{\mathrm{r}}$ can induce changes in PPF (Fioravante and Regehr, 2011). In the case of Munc13-3, altered presynaptic $\mathrm{Ca}^{2+}$ dynamics and/or SV recruitment rates had been likely candidates. Munc13-3 may strengthen the interaction of Munc13-1 [also present in GCs (Augustin et al., 1999b)] with RIM1 $\alpha$ (Dulubova et al., 2005). Similar to RIM1 $\alpha$ deficiency (Kintscher et al., 2013), loss of Munc13-3 would then lead to reduced presynaptic $\mathrm{Ca}^{2+}$ signals, which, in turn, alter $p_{\mathrm{r}}$ and PPF. However, our data (Fig. 3) and the fact that Munc13-3 does not contain the RIM1 $\alpha$ binding site present in Munc13-1 (Lipstein et al., 2012) make such an effect unlikely.

Regarding SV recruitment rates, Munc13-3 may affect replenishment of released SVs. Depending on the speed of replenishment (Hallermann and Silver, 2013), either facilitation [replenishment on the timescale of the stimulus interval, i.e., 10-100 ms (Valera et al., 2012)] and/or the failure rate (replenishment between stimulus repetitions, i.e., $\sim 5 \mathrm{~s}$ ) may be altered in Munc13-3 $3^{-1-}$ synapses. Chen et al. (2013) reported for the calyx of Held that combined loss of Munc13-2 and Munc13-3 increases $\mathrm{Ca}^{2+}$-dependent recovery from SV depletion. This effect occurred on a timescale of $>50 \mathrm{~ms}$ and, thus, is unlikely to be responsible for the increase in PPF observed at the much shorter ISIs used in our study (Fig. $1 \mathrm{~K}$ ) and in previous reports (Augustin et al., 2001; Beierlein et al., 2007; Bao et al., 2010). The effect on synaptic failures during ongoing stimulation would be a decrease rather than the observed increase (Fig. 1J). Furthermore, the slope of the cumulative charge during train stimulation would be expected to be significantly steeper in Munc13-3 $3^{-1-}$ synapses, an effect we did not observe (Fig. 5). Together, different from the calyx of Held, a role of Munc13-3 in SV recruitment is rather unlikely at GCs (Lee et al., 2013).

The discrepancy between the results of Chen et al. (2013) and our study may be interpreted on the background of the assumed differences in coupling distance between the site of $\mathrm{Ca}^{2+}$ influx 
A

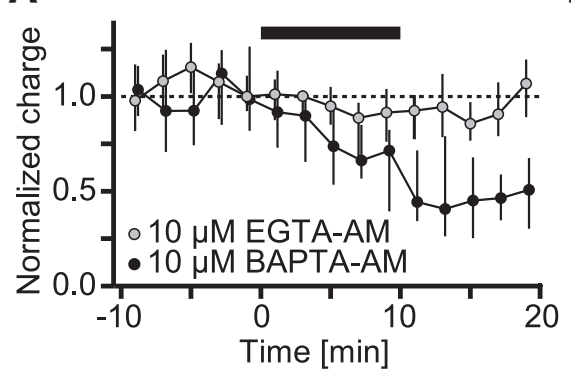

C
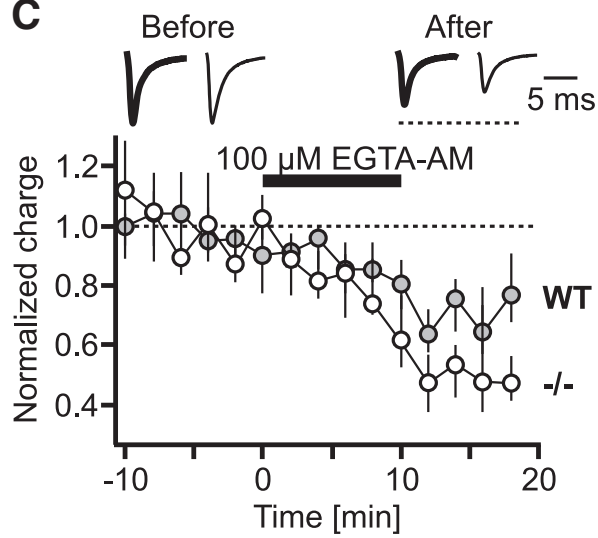

B

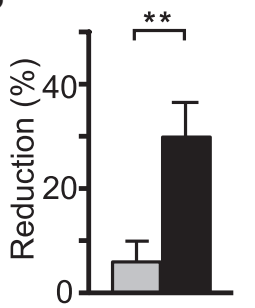

E. B.

(6) (6)

D
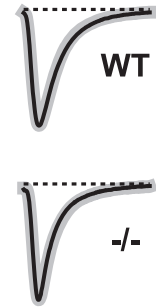

$\overline{5 \mathrm{~ms}}$
E

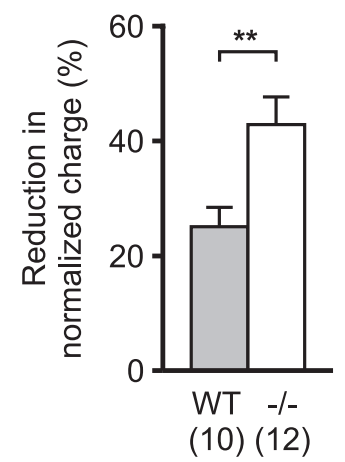

$\mathbf{F}$

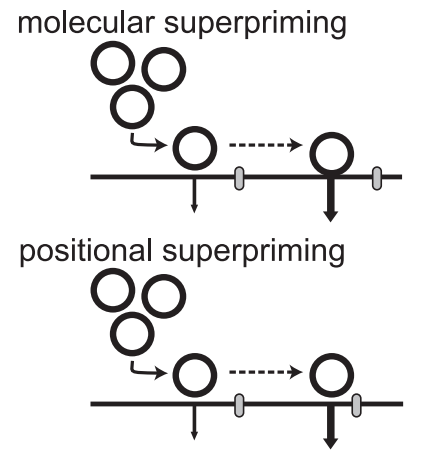

Figure 6. Stronger effect of EGTA on release in Munc $13-3^{-/-}$synapses. $A$, Charges of tEPSCs during bath application of $10 \mu \mathrm{m}$ EGTA-AM or BAPTA-AM (gray and black symbols, respectively; thick black bar) in two exemplary WT cells. The tEPS(s were evoked every $5 \mathrm{~s}$, and charges were binned in $2 \mathrm{~min}$ intervals and normalized to the average of the control period ( -10 to $0 \mathrm{~min}$ ), given as median and IQR. B, Average reduction of tEPSC charge (averaged over the $10-20$ min period after EGTA- or BAPTA-AM application) by $10 \mu \mathrm{M}$ EGTA- and BAPTA-AM (E. and B., respectively; mean $\pm S E M$; ${ }^{* *} p=0.010, t$ test). C, Bottom, Charge of tEPSCs during bath application of $100 \mu \mathrm{m}$ EGTA-AM in an exemplary WT and Munc13-3 $^{-/-}$cell (gray and open symbols, respectively). Top traces, Average tEPSCs before and after (10 - $20 \mathrm{~min}$ ) EGTA-AM application (thick line, WT; thin line, Munc $13-3^{-/-}$; stimulation artifacts are blanked for clarity). D, Grand averages of tEPSCs during EGTA-AM application (thick gray lines, control period; thin black lines, after EGTA-AM application; each trace was selfnormalized to its peak amplitude; WT, $n=10$ cells; Munc13-3 ${ }^{-/-}, n=12$ cells). Note that EGTA did not affect the waveform of tEPSCS. $E$, Average reduction of tEPSC charge by $100 \mu \mathrm{m}$ EGTA-AM (mean \pm SEM; ${ }^{* *} p=0.009, t$ test). $\boldsymbol{F}$, Scheme illustrating two alternative hypotheses on the role of Munc13-3 at GC-BC synapses. Top, Molecular superpriming: vesicles are docked and primed into fusion-competent vesicles having a low $p_{\mathrm{r}}$ of $\sim 0.2$ (corresponding to Munc $13-1^{-/-}$synapses). Munc13-3 superprimes vesicles (dashed arrow) by moving them closer to the plasma membrane, thereby increasing their $p_{\mathrm{r}}$ to $\sim 0.4$ (corresponding to fully matured vesicles in the WT situation). Bottom, Positional priming. In this scenario, Munc13-3 decreases the coupling distance between vesicles and release-driving $\mathrm{Ca}^{2+}$ channels (gray boxes). and the release sensor at the respective synapses. Thus, the Munc13-3-dependent priming step that increases $p_{\mathrm{r}}$ at GC synapses, which operate with comparable tight coupling (Fig. 6A, B; Schmidt et al., 2013), may hinder rapid SV replenishment at the young calyx of Held, which operates with microdomain coupling (Meinrenken et al., 2002). This scenario may shed light on the temporal sequence of SV priming in microdomain coupling (Haucke et al., 2011) and would indicate that Munc13-3 may also superprime SVs in the mature calyx of Held, a synapse that tightens influx-release coupling during postnatal development (Fedchyshyn and Wang, 2005).

The molecular details of Munc13-3-dependent superpriming remain rather unclear. Munc13-3 is the only Munc13 isoform that is coexpressed with Munc13-1 in GCs (Augustin et al., 1999b). Given the fact that, in Munc13-1 deficient mice, only homozygotes but not heterozygotes showed a synaptic phenotype (Augustin et al., 1999a), it can be assumed that the amount of Munc13-1 in WT presynaptic terminals is not limiting priming, and therefore, Munc13-3 does not simply sum up with Munc13-1 as a general priming factor. Similarly, the finding that Munc13-1 (Augustin et al., 1999a), but not Munc13-3 (Augustin et al., 2001), is essential for SV priming at excitatory synapses indicates specific roles for the two proteins. Thus, the specific functions of Munc13-3 must reside in its differences to, not its homologies with, Munc13-1. Differences are mainly found in their N termini. Here, Munc13-1 harbors an RIM-binding and a $\mathrm{Ca}^{2+} /$ calmodulin (CaM)-binding domain. The substantially larger $\mathrm{N}$ terminus of Munc13-3 lacks these domains but harbors two other $\mathrm{Ca}^{2+} / \mathrm{CaM}$-binding sites (Lipstein et al., 2012). The lacking RIM-binding domain cannot explain the superpriming effect of Munc13-3 because interaction of RIM with Munc13s is known to increase rather than decrease $p_{\mathrm{r}}$ (Kintscher et al., 2013). Thus, the two distinct CaM-binding domains of Munc13-3 may be involved in increasing $p_{\mathrm{r}}$. However, so far, interaction partners specific to the $\mathrm{N}$ terminus of Munc13-3 have not been identified (Lipstein et al., 2012).

Independently of information about Munc13-3-specific binding partners, two scenarios may mechanistically explain Munc13-3-dependent superpriming. Either the coupling between $\mathrm{Ca}^{2+}$ channels and release sensor may be tightened (positional superpriming) or the intrinsic $\mathrm{Ca}^{2+}$ affinity of the release sensor may be increased (molecular superpriming). The stronger effect of high concentrations of EGTA in Munc13-3 $3^{-1-}$ synapses compared with the WT (Fig. 6C) may be taken as evidence for the former hypothesis (Eggermann et al., 2012). Based on our previous analysis of WT synapses between GCs and PCs (Schmidt et al., 2013), Munc13-3 is then expected to reduce the coupling distance by $10-15 \mathrm{~nm}$. For this difference in coupling distance, the changes in synaptic delay, half-duration of EPSCs, and relative contribution of delayed release would be too small to be resolvable $[<100 \mu \mathrm{s},<50 \mu \mathrm{s}$, and $<0.01 \%$, respectively (Eggermann et al., 2012)], but it would nonetheless induce the observed change in $p_{\mathrm{r}}$. However, our data do not allow ruling out the second scenario of the action of Munc13-3, i.e., an increase in the intrinsic $\mathrm{Ca}^{2+}$ affinity of the release sensor. Also in this scenario, $\mathrm{Ca}^{2+}$ buffering by large amounts of EGTA would yield a reduced transmitter release. Distinguishing these two scenarios requires experimental approaches [prolonged dialysis with exogenous buffers at known concentrations (Eggermann et al., 2012) and/or $\mathrm{Ca}^{2+}$ uncaging (Kochubey et al., 2009)], which, unfortunately, are technically not yet feasible at GC terminals.

The potency for superpriming may indicate a functional role for Munc13-3 in the context of network maturation. Similar to 
the visual cortex, in which Munc13-3 expression is tightly correlated with the critical period (Yang et al., 2007), Munc13-3 may shape the network characteristics of the mature cerebellar cortex. GCs respond to sensory stimulation with brief bursts of APs (Chadderton et al., 2004), for which changes in $p_{\mathrm{r}}$ induce a redistribution of synaptic efficacy within the burst (Markram and Tsodyks, 1996). Given the target cell-specific effects of Munc13-3 on GC outputs, which are strongest for BCs (Beierlein et al., 2007; Bao et al., 2010), superpriming may thus provide BCs with additional temporal lead (Blot and Barbour, 2014) for inhibiting PCs, which also receive direct excitatory GC input. Such subtle, superpriming-dependent effects may become necessary as soon as the GC-PC connectivity is established and PCs obtain their mature GABAergic responsiveness (Eilers et al., 2001). Clearly, more information on the developmental regulation (Augustin et al., 1999b) and synapse-specific targeting of Munc13-3 will be necessary to gain a deeper understanding of Munc13-3 functional roles.

The differential effects of Munc13-3 on the $\mathrm{Ca}^{2+}$-dependent replenishment of SVs (Chen et al., 2013) and on the $p_{\mathrm{r}}$ (Fig. 2) are reminiscent of the differential effects of Munc13-1, which also controls both the size of the RRP and $p_{\mathrm{r}}$ (Rhee et al., 2002). Notably, the $\mathrm{C} 1$ domain responsible for these effects is also present in Munc13-3. However, although $p_{\mathrm{r}}$ is decreased by Munc13-1 (Rhee et al., 2002), our data show that it is increased by Munc13-3. Thus, differential effects on the RRP and $p_{\mathrm{r}}$ represent an emerging principle of as yet unexplained molecular nature that extends the spectrum of functions executed by Munc13s.

\section{References}

Augustin I, Rosenmund C, Südhof TC, Brose N (1999a) Munc13-1 is essential for fusion competence of glutamatergic synaptic vesicles. Nature 400: 457-461. CrossRef Medline

Augustin I, Betz A, Herrmann C, Jo T, Brose N (1999b) Differential expression of two novel Munc13 proteins in rat brain. Biochem J 337:363-371. CrossRef Medline

Augustin I, Korte S, Rickmann M, Kretzschmar HA, Südhof TC, Herms JW, Brose N (2001) The cerebellum-specific Munc13 isoform Munc13-3 regulates cerebellar synaptic transmission and motor learning in mice. J Neurosci 21:10-17. Medline

Bao J, Reim K, Sakaba T (2010) Target-dependent feedforward inhibition mediated by short-term synaptic plasticity in the cerebellum. J Neurosci 30:8171-8179. CrossRef Medline

Barbour B (1993) Synaptic currents evoked in Purkinje cells by stimulating individual granule cells. Neuron 11:759-769. CrossRef Medline

Beierlein M, Fioravante D, Regehr WG (2007) Differential expression of posttetanic potentiation and retrograde signaling mediate targetdependent short-term synaptic plasticity. Neuron 54:949-959. CrossRef Medline

Betz A, Thakur P, Junge HJ, Ashery U, Rhee JS, Scheuss V, Rosenmund C, Rettig J, Brose N (2001) Functional interaction of the active zone proteins Munc13-1 and RIM1 in synaptic vesicle priming. Neuron 30:183196. CrossRef Medline

Blot A, Barbour B (2014) Ultra-rapid axon-axon ephaptic inhibition of cerebellar Purkinje cells by the pinceau. Nat Neurosci 17:289-295. CrossRef Medline

Brose N, Rosenmund C, Rettig J (2000) Regulation of transmitter release by Unc-13 and its homologues. Curr Opin Neurobiol 10:303-311. CrossRef Medline

Bucurenciu I, Kulik A, Schwaller B, Frotscher M, Jonas P (2008) Nanodomain coupling between $\mathrm{Ca}^{2+}$ channels and $\mathrm{Ca}^{2+}$ sensors promotes fast and efficient transmitter release at a cortical GABAergic synapse. Neuron 57:536-545. CrossRef Medline

Chadderton P, Margrie TW, Häusser M (2004) Integration of quanta in cerebellar granule cells during sensory processing. Nature 428:856-860. CrossRef Medline

Chen Z, Cooper B, Kalla S, Varoqueaux F, Young SM Jr (2013) The Munc13 proteins differentially regulate readily releasable pool dynamics and calcium-dependent recovery at a central synapse. J Neurosci 33:83368351. CrossRef Medline

Clements JD, Silver RA (2000) Unveiling synaptic plasticity: a new graphical and analytical approach. Trends Neurosci 23:105-113. CrossRef Medline

Cooper B, Hemmerlein M, Ammermüller J, Imig C, Reim K, Lipstein N, Kalla S, Kawabe H, Brose N, Brandstätter JH, Varoqueaux F (2012) Munc13independent vesicle priming at mouse photoreceptor ribbon synapses. J Neurosci 32:8040-8052. CrossRef Medline

Dulubova I, Lou X, Lu J, Huryeva I, Alam A, Schneggenburger R, Südhof TC, Rizo J (2005) A Munc13/RIM/Rab3 tripartite complex: from priming to plasticity? EMBO J 24:2839-2850. CrossRef Medline

Eggermann E, Bucurenciu I, Goswami SP, Jonas P (2012) Nanodomain coupling between $\mathrm{Ca}^{2+}$ channels and sensors of exocytosis at fast mammalian synapses. Nat Rev Neurosci 13:7-21. CrossRef Medline

Eilers J, Plant TD, Marandi N, Konnerth A (2001) GABA-mediated Ca ${ }^{2+}$ signalling in developing cerebellar Purkinje neurones. J Physiol 536:429437. CrossRef Medline

Fedchyshyn MJ, Wang LY (2005) Developmental transformation of the release modality at the calyx of Held synapse. J Neurosci 25:4131-4140. CrossRef Medline

Fioravante D, Regehr WG (2011) Short-term forms of presynaptic plasticity. Curr Opin Neurobiol 21:269-274. CrossRef Medline

Hallermann S, Silver RA (2013) Sustaining rapid vesicular release at active zones: potential roles for vesicle tethering. Trends Neurosci 36:185-194. CrossRef Medline

Hallermann S, Fejtova A, Schmidt H, Weyhersmüller A, Silver RA, Gundelfinger ED, Eilers J (2010) Bassoon speeds vesicle reloading at a central excitatory synapse. Neuron 68:710-723. CrossRef Medline

Haucke V, Neher E, Sigrist SJ (2011) Protein scaffolds in the coupling of synaptic exocytosis and endocytosis. Nat Rev Neurosci 12:127-138. CrossRef Medline

Kaeser PS, Deng L, Wang Y, Dulubova I, Liu X, Rizo J, Südhof TC (2011) RIM proteins tether $\mathrm{Ca}^{2+}$ channels to presynaptic active zones via a direct PDZ-domain interaction. Cell 144:282-295. CrossRef Medline

Kalla S, Stern M, Basu J, Varoqueaux F, Reim K, Rosenmund C, Ziv NE, Brose N (2006) Molecular dynamics of a presynaptic active zone protein studied in Munc13-1-enhanced yellow fluorescent protein knock-in mutant mice. J Neurosci 26:13054-13066. CrossRef Medline

Kintscher M, Wozny C, Johenning FW, Schmitz D, Breustedt J (2013) Role of RIM $1 \alpha$ in short- and long-term synaptic plasticity at cerebellar parallel fibres. Nat Commun 4:2392. CrossRef Medline

Kochubey O, Han Y, Schneggenburger R (2009) Developmental regulation of the intracellular $\mathrm{Ca}^{2+}$ sensitivity of vesicle fusion and $\mathrm{Ca}^{2+}$-secretion coupling at the rat calyx of Held. J Physiol 587:3009-3023. CrossRef Medline

Lee JS, Ho WK, Neher E, Lee SH (2013) Superpriming of synaptic vesicles after their recruitment to the readily releasable pool. Proc Natl Acad Sci U S A 110:15079-15084. CrossRef Medline

Lipstein N, Schaks S, Dimova K, Kalkhof S, Ihling C, Kölbel K, Ashery U, Rhee J, Brose N, Sinz A, Jahn O (2012) Nonconserved $\mathrm{Ca}^{2+} /$ calmodulin binding sites in Munc13s differentially control synaptic short-term plasticity. Mol Cell Biol 32:4628-4641. CrossRef Medline

Lipstein N, Sakaba T, Cooper BH, Lin KH, Strenzke N, Ashery U, Rhee JS, Taschenberger H, Neher E, Brose N (2013) Dynamic control of synaptic vesicle replenishment and short-term plasticity by $\mathrm{Ca}^{2+}$-CalmodulinMunc13-1 signaling. Neuron 79:82-96. CrossRef Medline

Malinow R, Tsien RW (1990) Presynaptic enhancement shown by wholecell recordings of long-term potentiation in hippocampal slices. Nature 346:177-180. CrossRef Medline

Markram H, Tsodyks M (1996) Redistribution of synaptic efficacy between neocortical pyramidal neurons. Nature 382:807-810. CrossRef Medline

Meinrenken CJ, Borst JG, Sakmann B (2002) Calcium secretion coupling at calyx of held governed by nonuniform channel-vesicle topography. J Neurosci 22:1648-1667. Medline

Meyer AC, Neher E, Schneggenburger R (2001) Estimation of quantal size and number of functional active zones at the calyx of held synapse by nonstationary EPSC variance analysis. J Neurosci 21:7889-7900. Medline

Neher E (1998) Usefulness and limitations of linear approximations to the understanding of $\mathrm{Ca}^{++}$signals. Cell Calcium 24:345-357. CrossRef Medline

Neher E, Sakaba T (2008) Multiple roles of calcium ions in the regulation of neurotransmitter release. Neuron 59:861-872. CrossRef Medline

Perkins KL (2006) Cell-attached voltage-clamp and current-clamp record- 
ing and stimulation techniques in brain slices. J Neurosci Methods 154: 1-18. CrossRef Medline

Redman S (1990) Quantal analysis of synaptic potentials in neurons of the central nervous system. Physiol Rev 70:165-198. Medline

Rhee JS, Betz A, Pyott S, Reim K, Varoqueaux F, Augustin I, Hesse D, Südhof TC, Takahashi M, Rosenmund C, Brose N (2002) $\beta$ phorbol ester- and diacylglycerol-induced augmentation of transmitter release is mediated by Munc13s and not by PKCs. Cell 108:121-133. CrossRef Medline

Salin PA, Malenka RC, Nicoll RA (1996) Cyclic AMP mediates a presynaptic form of LTP at cerebellar parallel fiber synapses. Neuron 16:797-803. CrossRef Medline

Schlüter OM, Basu J, Südhof TC, Rosenmund C (2006) Rab3 superprimes synaptic vesicles for release: implications for short-term synaptic plasticity. J Neurosci 26:1239-1246. CrossRef Medline

Schmidt H, Stiefel KM, Racay P, Schwaller B, Eilers J (2003) Mutational analysis of dendritic $\mathrm{Ca}^{2+}$ kinetics in rodent Purkinje cells: role of parvalbumin and calbindin $\mathrm{D}_{28 \mathrm{k}}$. J Physiol 551:13-32. CrossRef Medline

Schmidt H, Brachtendorf S, Arendt O, Hallermann S, Ishiyama S, Bornschein G, Gall D, Schiffmann SN, Heckmann M, Eilers J (2013) Nanodomain coupling at an excitatory cortical synapse. Curr Biol 23:244-249. CrossRef Medline

Schneggenburger R, Meyer AC, Neher E (1999) Released fraction and total size of a pool of immediately available transmitter quanta at a calyx synapse. Neuron 23:399-409. CrossRef Medline

Stevens CF, Wang Y (1994) Changes in reliability of synaptic function as a mechanism for plasticity. Nature 371:704-707. CrossRef Medline

Südhof TC (2013) Neurotransmitter release: the last millisecond in the life of a synaptic vesicle. Neuron 80:675-690. CrossRef Medline

Thorpe S, Fize D, Marlot C (1996) Speed of processing in the human visual system. Nature 381:520-522. CrossRef Medline

Trigo FF, Sakaba T, Ogden D, Marty A (2012) Readily releasable pool of synaptic vesicles measured at single synaptic contacts. Proc Natl Acad Sci U S A 109:18138-18143. CrossRef Medline

Valera AM, Doussau F, Poulain B, Barbour B, Isope P (2012) Adaptation of granule cell to Purkinje cell synapses to high-frequency transmission. J Neurosci 32:3267-3280. CrossRef Medline

Yang CB, Zheng YT, Li GY, Mower GD (2002) Identification of Munc 13-3 as a candidate gene for critical-period neuroplasticity in visual cortex. J Neurosci 22:8614-8618. Medline

Yang CB, Kiser PJ, Zheng YT, Varoqueaux F, Mower GD (2007) Bidirectional regulation of munc13-3 protein expression by age and dark rearing during the critical period in mouse visual cortex. Neuroscience 150:603608. CrossRef Medline 